Please quote as: Kipp, P.; Bittner, E. A. C.; Hoffmann, A.; Bretschneider, U. \& Leimeister, J. M. (2013): Collaborative Idea Elaboration on Web-Based Ideation Platforms. In: Eighth International Conference on Design Science Research in Information Systems and Technology (DESRIST), Helsinki, Finland. 


\title{
Collaborative Idea Elaboration on Web-Based Ideation Platforms
}

\author{
Philipp Kipp, Eva Bittner, Axel Hoffmann, Ulrich Bretschneider, \\ Jan Marco Leimeister \\ Kassel University, Information Systems, Kassel, Germany \\ \{philipp.kipp, bittner, axel.hoffmann, bretschneider, \\ leimeister\}@uni-kassel.de
}

\section{Introduction}

In recent years many companies have started integrating their customers into product and service development processes. This phenomenon is known as Open Innovation (OI). In OI research, especially the integration of customers into the early stages of product or service innovation has caught a lot of attention in theory and practice [1], [2]. Especially since the Internet as a simple way to communicate with a broad auditorium allows new forms of customer integration. Web-based innovation platforms (WBIP) for implementing Virtual Idea Communities or online Idea Competitions now allow all customers to share their insights, opinions and ideas regarding a product with the manufacturer or other customers [3].

Although WBIPs rely on customers to exchange their views, needs and opinions regarding the products, only few of them offer a structured process that guides them through the generation and elaboration process in a collaborative manner [3]. The next important step in the evolution of WBIP should focus on the design of the platform to ideally support contributors in generating good ideas. The success of collaborative approaches to problem solving and creativity suggests using structured collaboration on WBIP.

This paper develops a structured process to support groups of people in the collaborative elaboration of their ideas. The process goal is enhancing an initial idea into the description of a relevant problem and a possible solution to this problem. The research was guided by the following research question:

1. How can the idea elaboration in WBIP be improved by a repeatable collaboration process?

\section{Methodology}

The artefact designed in this paper is a tool supported collaborative idea elaboration process for web based ideation platforms. In order to develop the collaboration process we chose collaboration engineering methodology, as it aims at "designing collabo- 
rative work practices for high-value recurring tasks” [4]. The final process design was validated in three proof-of-concept sessions and showed significant improvement of ideas.

\section{Conclusion}

The collaboration process developed in this paper is an important step to successful collaborative idea elaboration on WBIP. The process was developed and evaluated following well established methodology from the field of collaboration engineering.

Collaboration Engineering and the collaboration process design approach provided the methodology for the development of collaborative processes. We used this body of knowledge to develop and pilot our collaborative idea elaboration process. The process is based on the separate identification and elaboration of the ideas underlying problem and its suggested solution by groups with knowledge in the ideas domain.

The evaluation by a jury of experts from the ideas' topic suggests that the overall quality of the idea improves during the collaboration process. Especially for the elaboration and originality of the ideas, the evaluation shows an increase in quality.

The theoretical contribution of this paper is that it is combining approaches from Information Systems, Collaboration Engineering and Innovation Management. Combining these three fields can enable an increase in idea quality and therefore strengthen the Open Innovation approach. From a practical perspective, this paper describes a step towards the implementation of collaboration tools on WBIP, thus enabling platform providers to foster collaboration and an increase of idea quality on their platforms. The results indicate that the collaborative idea elaboration process is a promising approach to improve idea quality.

This paper lays the foundation for our future research in user collaboration for WBIP. Future work will focus on improving the process and implementing it on an innovation community site at our university.

\section{References}

1. von Hippel, E.: Democratizing Innovation. The MIT Press, Cambridge, MA (2005)

2. Blohm, I., Bretschneider, U., Leimeister, J.M., Krcmar, H.: Does collaboration among participants lead to better ideas in IT-based idea competitions - An empirical investigation. International Journal of Networking and Virtual Organizations (2011)

3. Kipp, P., Wieck, E., Bretschneider, U., Leimeister, J.M.: 12 Years of GENEX Framework: What did Practice Learn from Science in Terms of Web-Based Ideation? 11. Internationale Tagung Wirtschaftsinformatik, Leipzig (2013)

4. De Vreede, G.-J., Briggs, R.O.: Collaboration Engineering: Designing Repeatable Processes for High-Value Collaborative Tasks. 38th Hawaii International Conference on System Sciences, (2005) 